\title{
Propofol exerts anti-inflammatory effects in rats with lipopolysaccharide-induced acute lung injury by inhibition of CD14 and TLR4 expression
}

\author{
Ling Ma ${ }^{1}$, Xiu-Ying $\mathrm{Wu}^{1}$, Li-Hong Zhang ${ }^{1}$, Wei-Min Chen ${ }^{1}$, Akinori Uchiyama ${ }^{2}$, \\ Takashi Mashimo ${ }^{2}$ and Yuji Fujino ${ }^{2}$ \\ ${ }^{1}$ Department of Anesthesiology, Shengjing Hospital, China Medical University, Shenyang, China \\ ${ }^{2}$ Department of Anesthesiology and Intensive Care Medicine, Osaka University Medical School, Osaka, Japan
}

\begin{abstract}
We investigated the effect of propofol (Prop) administration (10 mg kg $\mathrm{h}^{-1}$, intravenously) on lipopolysaccharide (LPS)induced acute lung injury and its effect on cluster of differentiation (CD) 14 and Toll-like receptor (TLR) 4 expression in lung tissue of anesthetized, ventilated rats. Twenty-four male Wistar rats were randomly divided into three groups of 8 rats each: control, LPS, and LPS+Prop. Lung injury was assayed via blood gas analysis and lung histology, and tumor necrosis factor- $\alpha$ $(\mathrm{TNF}-\alpha)$ and interleukin-1 $\beta$ (IL-1 $\beta$ ) levels were determined in bronchoalveolar lavage fluid using ELISA. Real-time polymerase chain reaction was used to detect CD14 and TLR4 mRNA levels, and CD14 and TLR4 protein expression was determined by Western blot. The pathological scores were $1.2 \pm 0.9,3.3 \pm 1.1$, and $1.9 \pm 1.0$ for the control, LPS, and LPS+Prop groups, respectively, with statistically significant differences between control and LPS groups $(P<0.05)$ and between LPS and LPS+Prop groups $(P<0.05)$. The administration of LPS resulted in a significant increase in TNF- $\alpha$ and IL-1 $\beta$ levels, $7-$ and $3.5-$ fold, respectively $(P<0.05)$, while treatment with propofol partially blunted the secretion of both cytokines $(P<0.05)$. CD14 and TLR4 mRNA levels were increased in the LPS group (1.48 \pm 0.05 and $1.26 \pm 0.03$, respectively) compared to the control group $(1.00 \pm 0.20$ and $1.00 \pm 0.02$, respectively; $P<0.05)$, while propofol treatment blunted this effect $(1.16 \pm 0.05$ and $1.12 \pm 0.05$, respectively; $P<0.05)$. Both CD14 and TLR4 protein levels were elevated in the LPS group compared to the control group $(\mathrm{P}<0.05)$, while propofol treatment partially decreased the expression of CD14 and TLR4 protein versus LPS alone $(\mathrm{P}<0.05)$. Our study indicates that propofol prevents lung injury, most likely by inhibition of CD14 and TLR4 expression.
\end{abstract}

Key words: CD14; Toll-like receptors; Propofol; Lipopolysaccharide; Lung injury

\section{Introduction}

Acute lung injury (ALI) and acute respiratory distress syndrome (ARDS) are major causes of acute respiratory failure, which increases the risk of morbidity and mortality in critically ill patients (1). Intratracheal instillation of lipopolysaccharide (LPS) in the rat is a well-characterized model (2-4) of $\mathrm{ALI}$, which in many important aspects closely resembles the clinical presentation of $\mathrm{ALI}$ and ARDS (5-7).

Despite intensive investigation in animals and patients, attempts to improve the outcome of ALI and associated organ disorders by modulating the inflammatory response have met with only limited success (8). Propofol (2,6-diisopropylphenol) has been commonly used to sedate intubated, mechanically ventilated ALI and ARDS patients because of the rapid onset and short duration of action, and rapid elimination. Additionally, increasing research findings have shown that propofol has anti-inflammatory effects. Propofol inhibits neutrophil functions, including chemotaxis, attachment, migration, phagocytosis, and the production of reactive oxygen species (ROS) (9). Propofol also suppresses pro-inflammatory cytokine production and inducible NO synthase/ NO biosynthesis in LPS-activated macrophages (10). Although propofol's mechanism of action remains elusive, it may modulate the immune system and, hence, bear great significance for patient care (11-13).

Accordingly, the most important LPS receptors on immunocompetent cells are cluster of differentiation (CD) 
14 and Toll-like receptors (TLRs), which play pivotal roles in triggering the innate immune system in hosts. Furthermore, TLR4 is a widely distributed LPS receptor in lung tissue (14). Finally, recent reports have shown that the inflammatory response to LPS is largely mediated by CD14 and TLR4 (15). Therefore, we designed a study to explore whether ALI is improved by propofol administration and to elucidate its possible mechanism of action in LPS-induced ALI in anesthetized, ventilated rats.

\section{Material and Methods}

All animal experiments were performed with the approval of the Animal Care and Use Committee of China Medical University, Shenyang, China.

\section{Animal preparation}

Twenty-four male Wistar rats weighing $332 \pm 28 \mathrm{~g}$ and aged 8-11 weeks were randomly divided into three groups of 8 rats each: control, LPS, and LPS+propofol (Prop). The rat model of LPS-induced lung injury used in the present study was described in detail in previous reports (2-4). In all groups, anesthesia was induced with $50 \mathrm{mg} / \mathrm{kg}$ pentobarbital sodium administered intraperitoneally and maintained with $12 \mathrm{mg} \mathrm{kg}^{-1} \mathrm{~h}^{-1}$ pentobarbital sodium via the left jugular vein; neuromuscular blockage was achieved by intravenous administration of $0.4 \mathrm{mg} \mathrm{kg}^{-1} \mathrm{~h}^{-1}$ pipecuronium bromide (Gedeon Richter Ltd., Hungary). Rats were placed on a heating pad to maintain body core temperature at $37^{\circ} \mathrm{C}$ and tracheal cannulation (14 gauge) was performed after tracheotomy. The right carotid artery was catheterized for continuous arterial blood pressure measurements and blood sampling. Heart rate (HR) was obtained by electrocardiographic lead monitoring using transducers (Gould, USA). Blood gases were measured with an automated analyzer (Bayer 855 Rapidlab; Siemens, Belgium) immediately after blood samples were drawn.

The animals were ventilated under the following conditions: pressure-controlled ventilation, peak inspiratory pressure of $14 \mathrm{cmH}_{2} \mathrm{O}$, positive end-expiratory pressure of $5 \mathrm{cmH}_{2} \mathrm{O}$ and respiratory rate of 70 breaths/ min, 1:2 inspiratory:expiratory ratio, and $100 \%$ fraction of inhaled oxygen (Servo 900C ventilator; Siemens-Elema, Sweden).

\section{Experimental protocol}

After 30 min of mechanical ventilation to ensure that the animals were in stable condition, a baseline set of $H R$, mean arterial pressure (MAP), and blood gas measurements was obtained. Thereafter, $5 \mathrm{mg} / \mathrm{kg}$ LPS (055:B5; L-2880, Sigma Chemical Co., USA) was instilled intratracheally in LPS and LPS+Prop groups. Infusion of either phosphate-buffered saline (PBS) or propofol (10 $\mathrm{mg} \mathrm{kg}^{-1} \mathrm{~h}^{-1}$, AstraZeneca, Italy) was started during intratracheal instillation of LPS. This intravenous infusion continued until the end of the 5-h protocol. The animals in the control group were treated with exactly the same protocol as the LPS group, except that they received an intratracheal instillation of PBS instead of LPS.

At $5 \mathrm{~h}$ after intratracheal instillation, MAP and HR were recorded and blood gas analysis was performed. Thereafter, all rats were euthanized with a lethal injection of pentobarbital, the thorax was opened, and the lungs were removed en bloc.

\section{Lung histology by light microscopy}

The lower lobe of the right lung from each animal was immersed in $10 \%$ buffered neutral formaldehyde fixative for $24 \mathrm{~h}$ and embedded in paraffin. A series of $4-\mu \mathrm{M}$ sections were cut and stained with hematoxylin and eosin. Slides were viewed with a Nikon SMZ 1500 Microscope (Nikon, Japan) to observe histological changes. Edema, hemorrhage, wall thickness, hyperinflation, and infiltration of inflammatory cells in alveolar spaces were scored on a scale of $0-4$ : 0 for normal lungs, 1 for $<25 \%$ lung involvement, 2 for $25-50 \%$ involvement, 3 for $50-75 \%$ involvement, and 4 for $>75 \%$ involvement. The total histology score is the sum score of all parameters.

\section{Lung lavage analysis}

The left lung harvested from each rat was infused with $5 \mathrm{~mL}$ PBS at room temperature, which was withdrawn, and reinfused two more times. There were no differences in the volume of saline recovered $(4.2 \pm 0.4 \mathrm{~mL}$ fluid) after the lung lavage process between the three experimental groups. Bronchoalveolar lavage fluid (BALF) was centrifuged at $1200 \mathrm{~g}$ for $10 \mathrm{~min}$ at $4^{\circ} \mathrm{C}$. The supernatant was separated into aliquots and frozen at $-30^{\circ} \mathrm{C}$ for batch analysis via enzyme-linked immunosorbent assay (ELISA). The levels of tumor necrosis factor (TNF)- $\alpha$ and interleukin (IL)-1 $\beta$ were later determined using rat TNF- $\alpha$ and IL- $1 \beta$ ELISA kits (both from R\&D Systems Inc., USA) according to manufacturer instructions. Samples taken from each animal (8 per group) were analyzed in triplicate for TNF- $\alpha$ and IL-1 $\beta$.

\section{Real-time polymerase chain reaction (PCR)}

Lung parenchyma strips were cut longitudinally from the middle lobe of the right lung. Following manufacturer instructions, total RNA was isolated from the frozen lung tissue using Trizol reagent (Promega, USA) and then reverse transcribed with the BcaBest RNA PCR kit (TaKaRa Biotechnology, China). Real-time PCR was then performed after combining SYBR Green Master Mix, forward and reverse primers, and cDNA. Preliminary analyses showed that glyceraldehyde-3-phosphate dehydrogenase (GAPDH) and $\beta$-actin had a similar efficiency when used as the housekeeping gene (data not shown). For the current study, we chose GAPDH. The oligonucleotide primers (Sangon Biotech Co. Ltd., China) used for real-time PCR are shown in Table 1. Real-time PCR 
Table 1. PCR primers for RT-PCR.

\begin{tabular}{lc}
\hline cDNA & Primer sequences \\
\hline CD14 & Forward: 5'-GGAAACCTAGGCCAGAGGGA-3' \\
& Reverse: 5'-AGCAAAGCCAAAGTTCCTGA-3' \\
TLR4 & Forward: 5'-GAGGACTGGGTGAGAAACGA-3' \\
& Reverse: 5'-GAAACTGCCATGTCTGAGCA-3' \\
GAPDH & Forward: 5'-ATGTTCCAGTATGACTCCACTCACG-3' \\
& Reverse: 5'-GAAGACACCAGTAGACTCCACGACA-3' \\
\hline
\end{tabular}

cDNA = complementary DNA; CD14 = cluster of differentiation 14; TLR4 = Toll-like receptor 4 ; GAPDH = glyceraldehyde-3phosphate dehydrogenase.

was performed in triplicate for each sample. The thermal cycling conditions were as follows: 1 cycle of $10 \mathrm{~s}$ at $95^{\circ} \mathrm{C}$, 45 cycles of $95^{\circ} \mathrm{C}$ for $5 \mathrm{~s}$ and $60^{\circ} \mathrm{C}$ for $20 \mathrm{~s}$, followed by a standard melting curve analysis. Annealing temperatures were optimized for each primer pair used. The cycle threshold value within the linear exponential increase phase was used to determine the original copy number of the DNA template. As an internal control and for normalization purposes, along with characterization of CD14 and TLR4 expression for each sample, the level of mRNA expression for GAPDH was simultaneously measured. Real-time PCR was performed in a Rotor-Gene 2000 instrument (Corbett Robotics, Australia).

\section{Western blot analysis of CD14 and TLR4}

Protein was extracted from the frontal lobe of each right lung and protein content was determined by the Bradford method. Each homogenate was then diluted with PBS to obtain equal protein concentrations. Then, $20 \mu \mathrm{g}$ protein per lane was separated on a $10 \%$ polyacrylamide gel and transferred to a nitrocellulose membrane (BioRad, USA). The transfers were blocked overnight with $5 \%$ $(\mathrm{v} / \mathrm{v})$ skim milk at $4^{\circ} \mathrm{C}$. The membranes were then incubated with anti-CD14 (sc-9150), anti-TLR4 (sc16240), or anti- $\beta$-actin (sc-47778) antibodies (Santa Cruz Biotechnology, USA) at 1:200 dilution for $2 \mathrm{~h}$ at $37^{\circ} \mathrm{C}$. After being washed 3 times in PBST, the membranes were incubated with 1:2000 horseradish peroxidase-conjugated anti-rabbit, -goat, or -mouse IgGs (Pierce, USA) for $1 \mathrm{~h}$ at room temperature. The blots were developed using the enhanced chemiluminescence detection system. The relative band density was determined with the Scion imaging system (Scion Corporation, USA). Gel loadings were normalized to $\beta$-actin levels.

\section{Statistical analysis}

Data are reported as means $\pm S D$; $n$ is the number of animals in each study group. Intragroup comparisons were performed by ANOVA, followed by the Tukey post hoc test when differences were significant. Values of $\mathrm{P}<$ 0.05 were considered to be statistically significant. The SPSS 13.0 software (SPSS Inc., USA) was used for all statistical analyses.

\section{Results}

All rats survived for the duration of the study. As shown in Table 2, in the control group HR, MAP, $\mathrm{PaO}_{2}$, and $\mathrm{PaCO}_{2}$ were stable before and after the experimental treatment. $\mathrm{HR}$ and $\mathrm{PaCO}_{2}$ were significantly increased at the end of the experiment in the LPS-treated group, while these effects were partially attenuated by propofol infusion. MAP and $\mathrm{PaO}_{2}$ were significantly decreased in the group with LPS-induced lung injury by the end of the experiment compared to the control group, and again these values were partially compensated for by propofol infusion (Table 2).

\section{Lung histology by light microscopy}

Histopathology revealed more alveolar edema, hemorrhage, wall thickening, hyperinflation, and infiltration of inflammatory cells into alveolar spaces in the LPS group when compared to the control group. These changes were less prominent in the rats receiving propofol compared to the LPS group (Figure 1). The pathological scores were $1.2 \pm 0.9,3.3 \pm 1.1$, and $1.9 \pm$

Table 2. Heart rate, mean arterial blood pressure, and blood gases of rats before intratracheal instillation and after $5 \mathrm{~h}$ of intratracheal instillation $(n=8)$.

\begin{tabular}{|c|c|c|c|c|c|c|}
\hline \multirow[t]{2}{*}{ Data } & \multicolumn{2}{|c|}{ Control } & \multicolumn{2}{|c|}{ LPS } & \multicolumn{2}{|c|}{ LPS+Prop } \\
\hline & Before & After & Before & After & Before & After \\
\hline HR (bpm) & $378 \pm 42$ & $383 \pm 60$ & $375 \pm 64$ & $432 \pm 25^{*},{ }^{* *}$ & $365 \pm 29$ & $393 \pm 51^{+}$ \\
\hline $\mathrm{MAP}(\mathrm{mmHg})$ & $134 \pm 13$ & $127 \pm 5$ & $130 \pm 16$ & $81 \pm 13^{*},{ }^{* *}$ & $127 \pm 10$ & $105 \pm 14^{* *},+$ \\
\hline $\mathrm{PaO}_{2}(\mathrm{mmHg})$ & $409 \pm 84$ & $404 \pm 89$ & $382 \pm 38$ & $151 \pm 43^{*}, * *$ & $366 \pm 45$ & $262 \pm 47^{* *},+$ \\
\hline $\mathrm{PaCO}_{2}(\mathrm{mmHg})$ & $30 \pm 6$ & $34 \pm 3$ & $37 \pm 10$ & $77 \pm 22^{*}$ & $32 \pm 6$ & $58 \pm 10^{* *},+$ \\
\hline
\end{tabular}

Data are reported as means \pm SD. In the control group, there was no significant difference before and after infusion of PBS. All data obtained at the "before" time point were similar to those for the control group. LPS = lipopolysaccharide; Prop = propofol; HR = heart rate; MAP $=$ mean arterial pressure. ${ }^{*} \mathrm{P}<0.05$ compared to control. ${ }^{*} \mathrm{P}<0.05$ compared to before. ${ }^{+} \mathrm{P}<0.05$ compared to LPS (repeated-measures ANOVA followed by the post hoc Tukey test). 

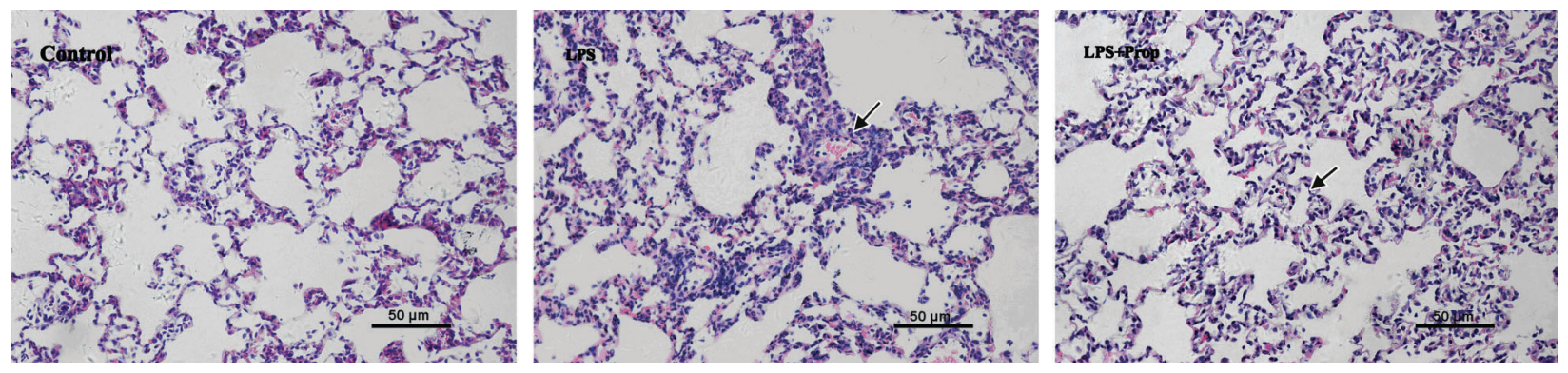

Figure 1. Histological findings for control (left), LPS (middle), and LPS+Prop (right) groups (H\&E stain). Significant alveolar edema, hemorrhage, wall thickening, hyperinflation, and infiltration of inflammatory cells in alveolar spaces can be seen in the LPS group (arrow). These changes were less prominent in the rats that received LPS+Prop (arrow). LPS = lipopolysaccharide; Prop $=$ propofol. Magnification bar $=50 \mu \mathrm{m}$.

1.0 for the control, LPS, and LPS+Prop groups, respectively, with statistically significant differences between control and LPS groups $(P<0.05)$ and between LPS and LPS+Prop groups $(P<0.05)$. Data are reported as means \pm SD for $n=4$ animals per group. This observation suggests that propofol at least partially reverses the lung injury caused by LPS injection.

\section{Effect of propofol on TNF- $\alpha$ and IL-1 $\beta$ concentration in BALF}

TNF- $\alpha$ and IL- $1 \beta$ levels in BALF were analyzed by ELISA in order to detect inflammation in the lungs of rats after administration of LPS. Figure 2 shows that very low levels of TNF- $\alpha$ and IL- $1 \beta$ were detected in the control group. Conversely, the administration of LPS resulted in a significant increase in TNF- $\alpha$ and IL-1 $\beta$ levels, 7 - and 3.5-

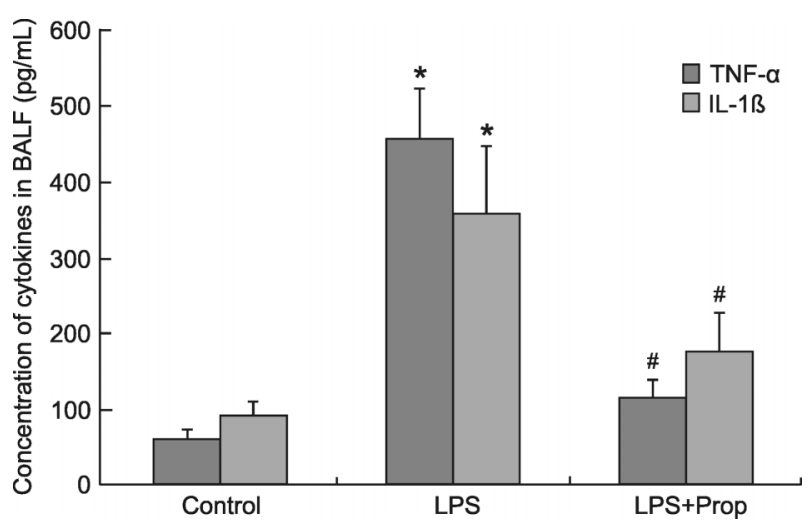

Figure 2. Concentration of TNF- $\alpha$ and IL-1 $\beta$ in bronchoalveolar lavage fluid (BALF). BALF samples were collected after each animal had received $5 \mathrm{~h}$ of intravenous LPS infusion, then examined by ELISA. Data are representative of triplicate experiments with similar results. Data are reported as means \pm SD for $n=8$ animals per experimental group. ${ }^{*} P<0.05$ compared to control; ${ }^{\#} \mathrm{P}<0.05$ compared to LPS group (ANOVA followed by the post hoc Tukey test). TNF- $\alpha=$ tumor necrosis factor- $\alpha$; IL-1 $\beta=$ interleukin-1 $\beta$; LPS = lipopolysaccharide; Prop $=$ propofol. fold, respectively $(P<0.05)$, while treatment with propofol partially blunted the secretion of both cytokines $(P<$ $0.05)$. Our data suggest that propofol partially decreases the levels of the inflammatory cytokines TNF- $\alpha$ and IL-1 $\beta$ in BALF caused by LPS injection.

\section{Effect of propofol on CD14 and TLR4 mRNA expression in lung tissues}

After intravenous infusion of propofol for $5 \mathrm{~h}$, lung homogenates were analyzed by real-time PCR to determine CD14 and TLR4 mRNA expression. The relative mRNA expression of CD14 and TLR4 was analyzed after normalization to GAPDH mRNA. Figure 3 shows that CD14 and TLR4 mRNA levels were increased in the LPS group compared to the control group $(P<0.05)$, while propofol treatment blunted this effect $(P<0.05)$.

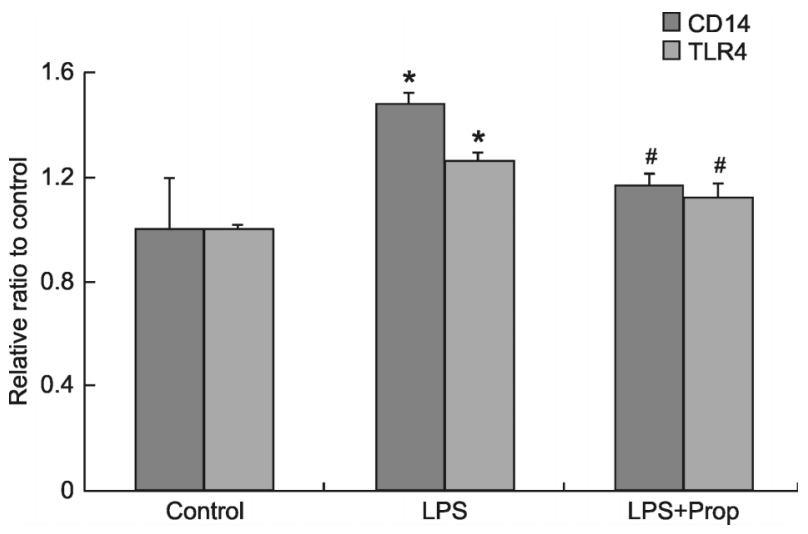

Figure 3. CD14 and TLR4 mRNA expression in lung tissue samples. Using real-time PCR, samples taken after each animal had received $5 \mathrm{~h}$ of intravenous LPS infusion were examined for CD14 and TLR4 mRNA expression. For each experimental condition, CD14 and TLR4 mRNA expression was normalized with GAPDH mRNA. Data are reported as means \pm SD for $n=8$ animals per experimental group. CD14 = cluster of differentiation 14; TLR4 = Toll-like receptor 4; LPS = lipopolysaccharide; Prop $=$ propofol. ${ }^{*} \mathrm{P}<0.05$ compared to control; ${ }^{\#} \mathrm{P}<0.05$ compared to LPS group (ANOVA followed by the post hoc Tukey test). 


\section{Effect of anesthetics on protein expression of CD14 and TLR4 in lung tissues}

We also examined CD14 and TLR4 protein expression in rat lung tissues by Western blot analysis of lung homogenates. CD14 and TLR4 protein expression was detected in all lung tissue samples from control and experimental rats (Figure 4A). Consistent with our realtime PCR data, Figure 4 shows that both CD14 and TLR4 protein levels were elevated in the LPS group compared to the control group $(P<0.05)$, while propofol treatment partially decreased the expression of CD14 and TLR4 protein versus LPS alone ( $\mathrm{P}<0.05$; Figure 4B).

\section{Discussion}

LPS is implicated as an important toxin that precipitates lung injury. Intratracheal LPS instillation provides a useful experimental system for investigating the immunopathological mechanisms of ALI and ARDS. As previously reported, in a mouse model of endotoxin-induced lung injury, pulmonary function was altered early, reaching maximum alteration at $4 \mathrm{~h}$ after endotoxin administration (16). In our model, we observed lung alteration at $5 \mathrm{~h}$ after LPS injection. The results of the present study showed that LPS is important in the pathogenesis of ALI and results in significant respiratory dysfunction and proinflammatory cytokine production, as well as elevated CD14 and TLR4 expression. Propofol, an intravenous anes-

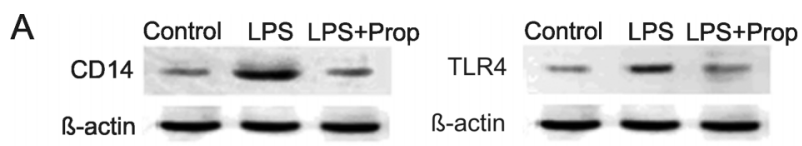

B

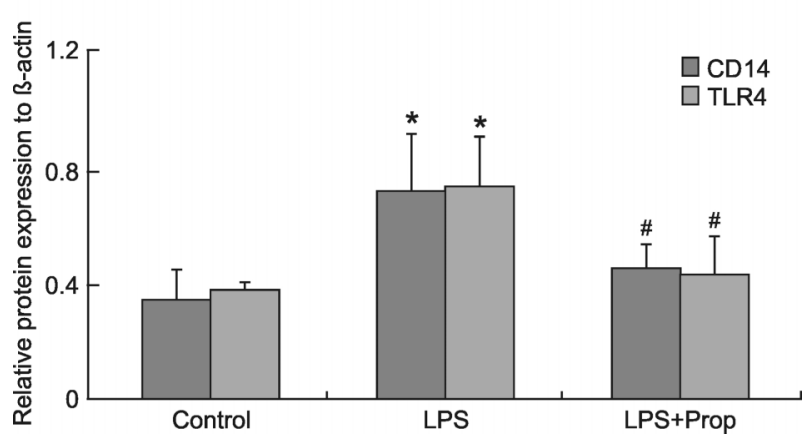

Figure 4. CD14 and TLR4 protein in rat lung. $A$, Representative Western blots are shown with the 54-kDa CD14 band, the 89-kDa TLR4 band, and the 43-kDa actin labeled band. $B$, Densitometry of all Western blot results from rat lungs of the control, LPS, and LPS+Prop groups. Densitometric values are presented as percentages of $\beta$-actin. Data are reported as means \pm SD for $\mathrm{n}=8$ animals per experimental group. LPS = lipopolysaccharide; Prop $=$ propofol. There was no significant difference between the control and LPS+Prop groups. * $\mathrm{P}<0.05$ compared to control; ${ }^{\#} \mathrm{P}<0.05$ compared to LPS group (ANOVA followed by the post hoc Tukey test) thetic and sedative, decreased CD14 and TLR4 expression, and alleviated $\mathrm{ALI}$ in anesthetized and ventilated rats.

In our study, hemodynamic parameters, blood gases, and histological scores significantly deteriorated in rats with LPS-induced ALI compared to control. In addition, TNF- $\alpha$ and IL- $1 \beta$ levels were increased in BALF in the rats receiving LPS. All of these data support the premise that rats develop pulmonary inflammation after administration of LPS.

LPS is a major initiator of host immune responses, triggering a physical interaction between CD14 and TLR4 (17-20). The CD14- and TLR4-mediated LPS signaling pathway then goes on to play a role in the regulation of alternative splicing of nuclear factor $-\kappa B(N F-\kappa B)$ in the lungs after injury. The role of CD14 and TLR4 in the regulation of immunity has been well defined in previous studies; for example, other groups have shown in their animal models that the extent of LPS-induced inflammatory cell recruitment in the airways correlated with the level of CD14 and TLR4 expression (21-24). Furthermore, He et al. (25) showed that inhibiting TLR4 expression by means of shRNA may decrease the severity of LPSinduced $\mathrm{ALI}$ and pulmonary fibrosis and subsequently improve the prognosis of the disease. In addition, our previous in vitro study, conducted on type II alveolar epithelial cells, showed that both CD14 and TLR4 mRNA and protein expression were increased after $3 \mathrm{~h}$ of incubation with LPS (26). Accordingly, the present study shows that LPS significantly increased CD14 and TLR4 mRNA expression as well as protein expression in vivo. In contrast, in a study by Jawan et al. (27), LPS increased CD14 and TLR4 gene expression, as well as the CD14 protein level, but not the TLR4 protein level in hepatocytes. Conversely, treatment of macrophages with LPS induced TLR4 protein and mRNA (28). Therefore, the mechanisms regulating CD14 and TLR4 expression in response to LPS may vary in different tissues and cell types.

Propofol is widely used as both an anesthetic for surgery and for the sedation of intubated and ventilated patients in the intensive care unit. It possesses antioxidant properties because its chemical structure includes a phenolic hydroxyl group, which chemically resembles the antioxidant $\alpha$-tocopherol (29). The commercially available propofol is mostly sold in combination with an intralipid solvent. Keeping this in mind, we have conducted this study using the same propofol that is commonly used in clinical practice. In previously published research, propofol treatment was reported to reduce the LPS-induced inflammatory responses in macrophages by inhibiting the interconnected ROS/Akt/IKkb/NF-KB signaling pathways (30). The present experiment aimed to investigate the effect of propofol on the expression of CD14 and TLR4 in lung tissue, since elevated CD14 is reported to be associated with increased infection and greater mortality 
in critically ill patients $(31,32)$ and the level of expression of TLR4 is closely associated with the extent of the acute pulmonary response to inhaled endotoxin (24). Our investigation strongly supports the anti-inflammatory effects of propofol in ALI: propofol improves LPS-induced $A L I$ in vivo by improving lung histological scores, decreasing inflammatory cytokine levels in BALF, and inhibiting CD14 and TLR4 gene and protein expression in lung tissue. These observations are consistent with our previous in vitro study (26), which showed that propofol can inhibit LPS-induced inflammatory responses in type II alveolar epithelial cells.

There are some drawbacks of our study that should be noted. First, since it is an in vivo experiment, we cannot absolutely conclude whether the anti-inflammatory effect of propofol on LPS-induced lung injury was directly mediated by propofol or indirectly through other mechanisms. Secondly, the relationship of CD14 and TLR4 expression with the downstream ROS/Akt/IKkb/NF-kB signaling pathways requires further study. The cytokine expression

\section{References}

1. Brun-Buisson C, Minelli C, Bertolini G, Brazzi L, Pimentel J, Lewandowski K, et al. Epidemiology and outcome of acute lung injury in European intensive care units. Results from the ALIVE study. Intensive Care Med 2004; 30: 51-61, doi: 10.1007/s00134-003-2022-6.

2. Van Helden HP, Kuijpers WC, Steenvoorden D, Go C, Bruijnzeel PL, Van Eijk M, et al. Intratracheal aerosolization of endotoxin (LPS) in the rat: a comprehensive animal model to study adult (acute) respiratory distress syndrome. Exp Lung Res 1997; 23: 297-316, doi: 10.3109/ 01902149709039228.

3. Brigham KL, Meyrick B. Endotoxin and lung injury. Am Rev Respir Dis 1986; 133: 913-927.

4. da Cunha AA, Nunes FB, Lunardelli A, Pauli V, Amaral RH, de Oliveira LM, et al. Treatment with $\mathrm{N}$-methyl-D-aspartate receptor antagonist (MK-801) protects against oxidative stress in lipopolysaccharide-induced acute lung injury in the rat. Int Immunopharmacol 2011; 11: 706-711, doi: 10.1016/ j.intimp.2011.01.016.

5. Honda K, Kobayashi H, Hataishi R, Hirano S, Fukuyama N, Nakazawa $\mathrm{H}$, et al. Inhaled nitric oxide reduces tyrosine nitration after lipopolysaccharide instillation into lungs of rats. Am J Respir Crit Care Med 1999; 160: 678-688.

6. Kermarrec N, Zunic P, Beloucif S, Benessiano J, Drouet L, Payen D. Impact of inhaled nitric oxide on platelet aggregation and fibrinolysis in rats with endotoxic lung injury. Role of cyclic guanosine $5^{\prime}$-monophosphate. Am J Respir Crit Care Med 1998; 158: 833-839.

7. Laffey JG, Honan D, Hopkins N, Hyvelin JM, Boylan JF, McLoughlin P. Hypercapnic acidosis attenuates endotoxininduced acute lung injury. Am J Respir Crit Care Med 2004; 169: 46-56, doi: 10.1164/rccm.200205-394OC.

8. Bhadade RR, de Souza RA, Harde MJ, Khot A. Clinical characteristics and outcomes of patients with acute lung injury and ARDS. J Postgrad Med 2011; 57: 286-290, doi: profile should be expanded and thoroughly studied to provide further hints as to the detailed mechanism of action of propofol, which needs further exploration. Thirdly, this study is limited in that we did not investigate the effect of propofol treatment on lung injury at different time points. This experiment, which could reveal additional therapeutic benefit of propofol depending on various time and dosing factors, will be conducted in the future.

The present study shows that administration of propofol greatly improves ALI (as evidenced by decreased histological alteration and inflammatory cytokine expression) and decreases the expression of CD14 and TLR4 in a rat model of LPS-induced lung injury. We suggest that the anti-inflammatory effects of propofol may proceed via the inhibition of CD14 and TLR4 expression.

\section{Acknowledgments}

Research supported by the Hospital Foundation of Shengjing Hospital, China Medical University, China.

10.4103/0022-3859.90077.

9. Marik PE. Propofol: an immunomodulating agent. Pharmacotherapy 2005; 25: 28S-33S, doi: 10.1592/ phco.2005.25.5_Part_2.28S.

10. Chen RM, Chen TG, Chen TL, Lin LL, Chang CC, Chang $\mathrm{HC}$, et al. Anti-inflammatory and antioxidative effects of propofol on lipopolysaccharide-activated macrophages. Ann N Y Acad Sci 2005; 1042: 262-271, doi: 10.1196/ annals.1338.030.

11. Chu CH, David LD, Hsu YH, Lee KC, Chen HI. Propofol exerts protective effects on the acute lung injury induced by endotoxin in rats. Pulm Pharmacol Ther 2007; 20: 503-512, doi: 10.1016/j.pupt.2006.03.006.

12. Kwak SH, Choi JI, Park JT. Effects of propofol on endotoxininduced acute lung injury in rabbit. J Korean Med Sci 2004; 19: 55-61, doi: 10.3346/jkms.2004.19.1.55.

13. Gao J, Zeng BX, Zhou LJ, Yuan SY. Protective effects of early treatment with propofol on endotoxin-induced acute lung injury in rats. $\mathrm{Br} J$ Anaesth 2004; 92: 277-279, doi: 10.1093/bja/aeh050.

14. Janardhan KS, Mclsaac M, Fowlie J, Shrivastav A, Caldwell $\mathrm{S}$, Sharma RK, et al. Toll like receptor-4 expression in lipopolysaccharide induced lung inflammation. Histol Histopathol 2006; 21: 687-696.

15. Pietrzak A, Wierzbicki M, Wiktorska M, BrzezinskaBlaszczyk E. Surface TLR2 and TLR4 expression on mature rat mast cells can be affected by some bacterial components and proinflammatory cytokines. Mediators Inflamm 2011; 2011: 427-473, doi: 10.1155/2011/427473.

16. Rojas M, Woods CR, Mora AL, Xu J, Brigham KL. Endotoxin-induced lung injury in mice: structural, functional, and biochemical responses. Am J Physiol Lung Cell Mol Physiol 2005; 288: L333-L341, doi: 10.1152/ ajplung.00334.2004.

17. da Silva Correia J, Soldau K, Christen U, Tobias PS, 
Ulevitch RJ. Lipopolysaccharide is in close proximity to each of the proteins in its membrane receptor complex. Transfer from CD14 to TLR4 and MD-2. J Biol Chem 2001; 276: 21129-21135, doi: 10.1074/jbc.M009164200.

18. Jiang Q, Akashi S, Miyake K, Petty HR. Lipopolysaccharide induces physical proximity between CD14 and toll-like receptor 4 (TLR4) prior to nuclear translocation of NFkappa B. J Immunol 2000; 165: 3541-3544.

19. Pugin J, Schurer-Maly CC, Leturcq D, Moriarty A, Ulevitch RJ, Tobias PS. Lipopolysaccharide activation of human endothelial and epithelial cells is mediated by lipopolysaccharide-binding protein and soluble CD14. Proc Natl Acad Sci U S A 1993; 90: 2744-2748, doi: 10.1073/ pnas.90.7.2744.

20. Sobottka Ventura AC, Engelmann K, Dahinden C, Bohnke $M$. Endotoxins modulate the autocrine function of organ cultured donor corneas and increase the incidence of endothelial cell death. Br J Ophthalmol 1997; 81: 10931098, doi: 10.1136/bjo.81.12.1093.

21. Togbe D, Schnyder-Candrian S, Schnyder B, Couillin I, Maillet I, Bihl F, et al. TLR4 gene dosage contributes to endotoxin-induced acute respiratory inflammation. J Leukoc Biol 2006; 80: 451-457, doi: 10.1189/jlb.0206099.

22. Phan HH, Cho K, Sainz-Lyon KS, Shin S, Greenhalgh DG. CD14-dependent modulation of NF-kappaB alternative splicing in the lung after burn injury. Gene 2006; 371: 121129, doi: 10.1016/j.gene.2005.11.019.

23. Akira S, Takeda K. Toll-like receptor signalling. Nat Rev Immunol 2004; 4: 499-511, doi: 10.1038/nri1391.

24. Jeyaseelan S, Chu HW, Young SK, Freeman MW, Worthen GS. Distinct roles of pattern recognition receptors CD14 and Toll-like receptor 4 in acute lung injury. Infect Immun 2005; 73: 1754-1763, doi: 10.1128/IAI.73.3.1754-1763.2005.

25. He Z, Zhu $Y$, Jiang $H$. Inhibiting toll-like receptor 4 signaling ameliorates pulmonary fibrosis during acute lung injury induced by lipopolysaccharide: an experimental study.
Respir Res 2009; 10: 126, doi: 10.1186/1465-9921-10-126.

26. Ma L, Wu X, Chen W, Fujino Y. Propofol has antiinflammatory effects on alveolar type II epithelial cells. Acta Anaesthesiol Scand 2010; 54: 362-369, doi: 10.1111/ j.1399-6576.2009.02127.x.

27. Jawan B, Kao YH, Goto S, Pan MC, Lin YC, Hsu LW, et al. Propofol pretreatment attenuates LPS-induced granulocytemacrophage colony-stimulating factor production in cultured hepatocytes by suppressing MAPK/ERK activity and NFkappaB translocation. Toxicol Appl Pharmacol 2008; 229: 362-373, doi: 10.1016/j.taap.2008.01.044.

28. Wu GJ, Chen TL, Chang CC, Chen RM. Propofol suppresses tumor necrosis factor-alpha biosynthesis in lipopolysaccharide-stimulated macrophages possibly through downregulation of nuclear factor-kappa B-mediated toll-like receptor 4 gene expression. Chem Biol Interact 2009; 180: 465-471, doi: 10.1016/j.cbi.2009.05.003.

29. Aarts L, van der Hee R, Dekker I, de Jong J, Langemeijer H, Bast $A$. The widely used anesthetic agent propofol can replace alpha-tocopherol as an antioxidant. FEBS Lett 1995; 357: 83-85, doi: 10.1016/0014-5793(94)01337-Z.

30. Tang J, Chen X, Tu W, Guo Y, Zhao Z, Xue Q, et al. Propofol inhibits the activation of p38 through up-regulating the expression of annexin $\mathrm{A} 1$ to exert its anti-inflammation effect. PLoS One 2011; 6: e27890, doi: 10.1371/journal. pone.0027890.

31. Fallavena PR, Borges TJ, Paskulin DD, Paludo FJ, Goetze TB, de Oliveira Jr, et al. The influences of CD14 -260C>T polymorphism on survival in ICU critically ill patients. Immunol Invest 2009; 38: 797-811, doi: 10.3109/ 08820130903258818.

32. Sutherland AM, Walley KR, Russell JA. Polymorphisms in CD14, mannose-binding lectin, and Toll-like receptor-2 are associated with increased prevalence of infection in critically ill adults. Crit Care Med 2005; 33: 638-644, doi: 10.1097/ 01.CCM.0000156242.44356.C5. 